\title{
Use of Acetylene Gas as Dienophile in a Diels-Alder Reaction
}
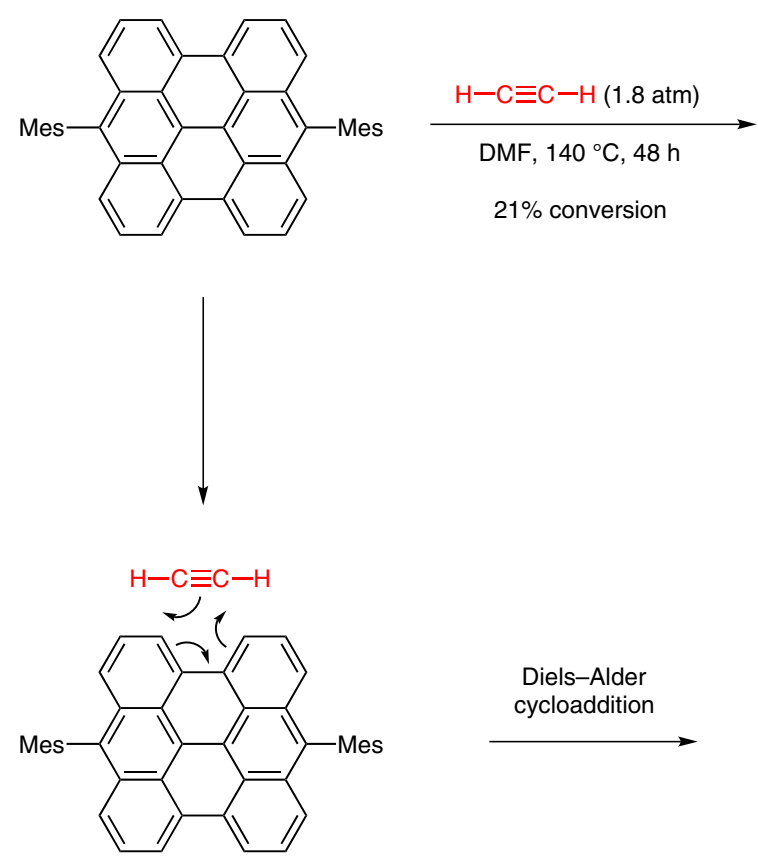

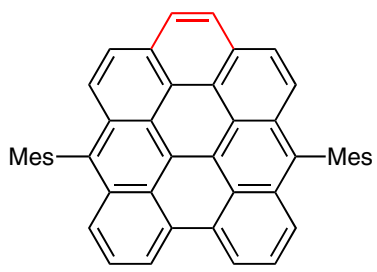

Diels-Alder cycloaddition
Significance: The use of acetylene gas as the dienophile in a cycloaddition Diels-Alder reaction to the bay region of a polyaromatic hydrocarbon is reported for the first time.
Comment: The sequence of cycloaddition followed by hydrogen elimination-rearomatization utilizing acetylene might prove to be a useful tool in the preparation of larger polyaromatic hydrocarbons, such as uniform carbon nanotubes, from small hydrocarbon templates.

\section{Category}

Synthesis of

Materials and

Unnatural Products

\section{Key words}

Diels-Alder reaction

acetylene

polycyclic aromatic hydrocarbons

\section{SYNFACTrenth}

